\title{
The Influence of Electron Beam Oscillation on the Crystallization and Structure of Dissimilar Steel-Bronze Welds
}

\author{
Tatiana Vasiljevna Olshanskaya ${ }^{1}$, Gleb Lvovich Permyakov ${ }^{1}$, Vladimir Yakovlevich Belenkiy ${ }^{1} \&$ Dmitriy \\ Nikolaevich Trushnikov ${ }^{1}$ \\ ${ }^{1}$ Perm National Research Polytechnic University, Russian Federation \\ Correspondence: Tatiana Vasiljevna Olshanskaya, Perm National Research Polytechnic University, 614990, \\ Perm, Komsomolsky Av., 29, Russian Federation.
}

Received: December 18, 2014

doi:10.5539/mas.v9n6p296

\author{
Accepted: January 14, $2015 \quad$ Online Published: May 30, 2015 \\ URL: http://dx.doi.org/10.5539/mas.v9n6p296
}

\begin{abstract}
The paper contains the findings of the metallographic study of dissimilar metal welds (steel 12X21H5T and bronze BrX-06) made by electron-beam welding (EBW) with beam modulation (transversal and X-shaped oscillation with triple beam splitting). The research shows that beam oscillation causes the metals to stir in the weld pool. As a result, welds have a very heterogeneous structure by width. X-shaped oscillation causes more intensive stirring than transversal oscillation. This leads to more homogenous stirring of crystallizing phases in the centre of the weld. The heterogeneous structure caused by beam oscillation gives the weld a very heterogeneous solidity both by width and depth. Triple beam splitting heated from bronze promotes the homogenous weld structure which is a fine-dispersed mechanical mixture of two systems: a eutectic based on copper and a mixture of solid solutions based on [alpha]-Fe and [gamma]-Fe. Such a structure makes the weld equalizes the solidity of the weld both by width and depth.
\end{abstract}

Keywords: physicochemical properties of metals, crystallization, weld pool, dissimilar welds, electron-beam welding, hydrodynamic processes, weld, oscillation of electron beam, beam splitting

\section{Introduction}

\subsection{The Theoretical and Experimental Aspects of "Steel-Bronze" Weld Crystallization in EBW}

In recent years, the nomenclature of dissimilar metal combinations used in welds increased rapidly, and it continues to broaden. The welds of different steel with copper and its alloys are widely used in many fields. As a rule, high-chromium steels (austenitic, austenitic-ferrite and martensite steel) and chromium bronzes are used for critical products, units and structures working in corrosive media at high or low temperature. There are very strict functionality requirements placed to such welds. However, they usually have chemical, structural and mechanical heterogeneousness which appears in various zones of the weld. Due to the fact that welded materials have different physicochemical properties the mechanical and operating characteristics of the weld are determined by the properties of a "new material" obtained by welding. That is why the main goal in welding of dissimilar metals is to regulate this process (Rabkin et al., 1975, Ryabov et al., 1984).

Considering processes in welding of dissimilar metals and alloys (melting; the formation and crystallization of a welding pool), should take into account the following physicochemical differences:

- Different melting temperature: if the difference is large, one metal becomes liquid when the other is still solid;

- Different linear expansion coefficient: causes considerable thermal stress. To reduce the thermal stress, is necessary to heat the material with lower linear expansion coefficient before welding;

- Different thermal conductivity and thermal capacity of welded metals: causes the asymmetry of thermal fields, changes the crystallization conditions for weld metal and determines the wettability of the most refractory metal. To offset the heat loss, one should heat the material with the highest thermal conductivity;

- Sharp distinction between the electromagnetic properties of welded metals: may cause the unsatisfactory quality of the weld;

- Differences in the nature of oxides, their chemical durability, melting temperature, ability to dissolve in the main metal, protective properties and also a different ability to dissolve gases (Rabkin et al., 1975, Ryabov et al., 
1984).

The metallurgical compatibility has a decisive influence on the weldability of dissimilar metals. The mutual solubility of liquid metals and the properties of liquid melts (toughness, density and wettability) determine the metallurgical compatibility. The chemical heterogeneity of welding pool depends on the liquid flow patterns and internal convective flows. Thus the difference of melts is of great importance. Besides, the solubility of metals in the solid state influences the weldability of dissimilar metals. The character of interaction between two metals can be inferred from the relevant state diagrams. However these diagrams are made for equilibrium conditions and correspond to a stable state, while welding is metastable process. That is why state diagrams allow imaging only the first approximate scheme of crystallization.

From the viewpoint of crystal physics, iron and copper have something in common: the type of crystal lattice at elevated temperatures; parameters; atomic radii; and the number of electrons in the outer layer of atom (Table 1). Thus copper and iron form solid solutions with restricted solubility (Figure 1). In iron-copper system, there are three areas of primary crystallization: [delta], [gamma] and [epsilon] and three transformations (two peritectic and one eutectoid) running at 1480,1094 and $850^{\circ} \mathrm{C}$. The solubility of iron in copper at $1025,900,800$ and $700^{\circ} \mathrm{C}$ is $2.5 ; 1.5 ; 0.9$ and $0.5 \%$ (by mass), respectively. At normal temperature, iron-copper alloys look like solid solutions of iron in copper ([epsilon]-phase, $\mathrm{Fe}<0.2 \%$ ), copper in [alpha]-iron $(<0.3 \% \mathrm{Cu}$ ) and the mixture of these solutions ([alpha]+[epsilon]) (Liakishev, 1997). When welding metals with restricted solid solubility, the quality of the weld depends on the degree of intracrystalline segregation during the primary crystallization of weld metal and on the character of further solid-state transformation of phase and structure. The solubility of iron goes down in copper alloys, thus the surplus iron begins to exude in a form of inclusions dressing by alloying elements and copper (Ryabov et al., 1984).

Table 1. The main physical and chemical properties of metals and melts.

\begin{tabular}{lcc}
\hline \multicolumn{1}{c}{ Parameter } & Copper & Iron \\
\hline Group in the Periodic Table & I & VII \\
Atomic number & 29 & 26 \\
Number of electrons in the outer layer of atoms & 1 & 2 \\
Type of crystal lattice & FCC & [alpha] $-\mathrm{BCC}$; [gamma] - FCC \\
Lattice parameter, nm & 0.361 & [alpha] -0.286 ; [gamma] - 0.365 \\
Atomic radius, nm & 0.128 & 0.141 \\
Melting temperature, $\mathrm{K}$ & 1356 & 1808 \\
Boiling temperature, $\mathrm{K}$ & 2840 & 3023 \\
Linear expansion coefficient per $1{ }^{\circ} \mathrm{C}$ & $16.6 \cdot 10^{-6}$ & $12 \cdot 10^{-6}$ \\
Thermal conductivity coefficient, $\mathrm{W} /(\mathrm{m} \cdot \mathrm{K})$ & 385 & 74 \\
Specific heat capacity, $\mathrm{J} /(\mathrm{kg} \cdot \mathrm{K})$ & 358 & 460 \\
Resistivity, Ohm $\cdot \mathrm{m}$ & $1.72 \cdot 10^{-8}$ & $12 \cdot 10^{-8}$ \\
Solid-state density, $\mathrm{g} / \mathrm{sm}^{3}$ & 8.93 & 7.87 \\
Liquid-state density, $\mathrm{g} / \mathrm{sm}^{3}$ & 8.00 & 7.00 \\
Dynamic viscosity of the melt, $\mathrm{N} \cdot \mathrm{s} / \mathrm{m}^{3}$ & $3.6 \cdot 10^{3}($ if $1375 \mathrm{~K}$ ) & $7 \cdot 10^{3}$ (if $1823 \mathrm{~K}$ ) \\
Surface tension of the $\mathrm{melt}, \mathrm{N} / \mathrm{m} \cdot 10^{-3}$ & 1103 (if $1454 \mathrm{~K}$ ) & 1500 (if $1793 \mathrm{~K}$ ) \\
\hline
\end{tabular}

Besides, the fusion welding of steels with copper alloys is complicated by a number of factors including a considerable difference in thermal properties; these are a lower viscosity and surface tension of the copper melt (Table 1); the inclination of copper to porosity; a high affinity of copper with oxygen causing eutectic $\mathrm{Cu}+\mathrm{Cu}_{2} \mathrm{O}$, which embrittles the metal. 


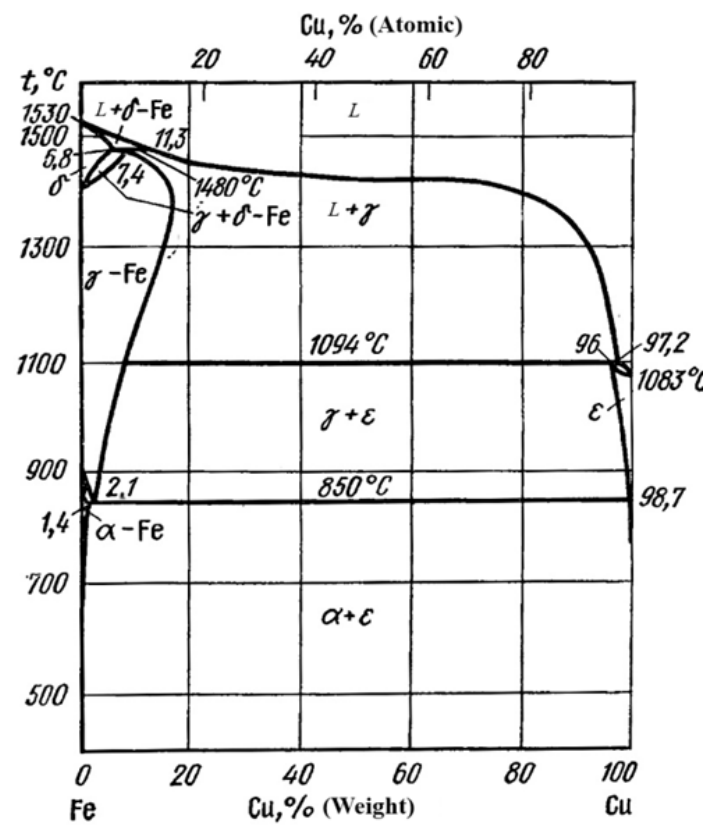

Figure 1. The state diagram for $\mathrm{Fe}-\mathrm{Cu}$ (Liakishev, 1997)

The main problem of steel weldability with copper alloys is the intercrystalline penetration of copper into steel. This defect looks like wedge-shaped cracks filled with copper, which often tales a group of grains. This defect considerably reduces the mechanical properties of steel and especially its plasticity. As a rule, the intercrystalline penetration of copper appears in welding with austenitic steel (Figure 2). A ferrite phase in steel reduces the penetration of copper. If the content of ferrite is over $30 \%$, the penetration is completely absent (Ryabov et al., 1984).

Studies show a relationship between the intercrystalline penetration of copper into steel and the hot cracks in steel. At the same time, there is no possibility to avoid these defects in welding for many steel grades without special processing methods. The processing methods that prevent hot pools in steel can also prevent the intercrystalline penetration of copper into steel (Volchenko, 1991).

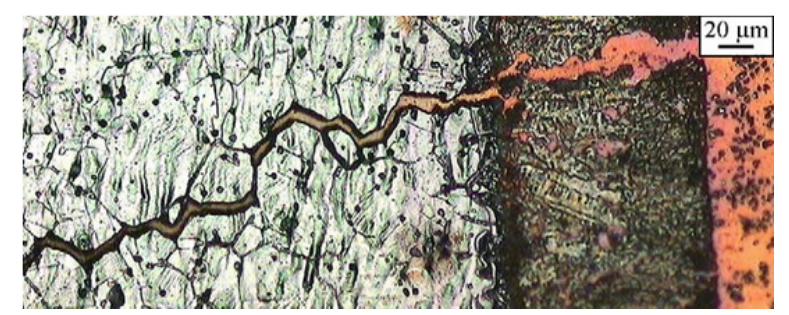

Figure 2. The intercrystalline penetration of copper into steel (Magnabosco et al., 2006)

The electron-beam welding (EBW) of steels with copper alloys solves many problems, for instance the reduction of copper porosity and the suppression of eutectic $\mathrm{Cu}+\mathrm{Cu}_{2} \mathrm{O}$ in it. This is because welding is carried out in a high vacuum. Besides, the highly concentrated injection of heat power and the possibility to position the electron beam precisely provide the high ratio of weld depth to width, the minimal size of heat-affected zone and high mechanical characteristics of welds.

However, the EBW of steel has a number of problems, yet not solved. They are associated with the formation of weld structure and defects in fusion zone and in weld root. Studies presented in papers (Goncharov et al., 2012, Magnabosco et al., 2006, Wielage et al., 2007) showed that, during the EBW of high-chromium steel with bronze by directing the beam along the junction of welded parts, a complex heterogeneous structure forms both by the width and depth of the weld. This worsens the operating characteristics of the weld because of the heterogeneous mechanical properties and low durability in corrosive media (Figures 3 and 4). 


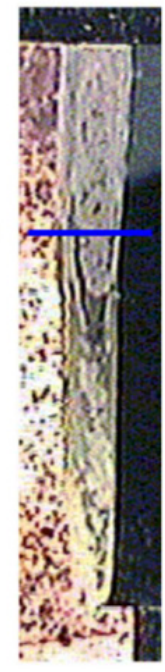

Figure 3. The weld of austenitic steel AISI 304L with copper, thickness 30mm (Magnabosco et al., 2006)
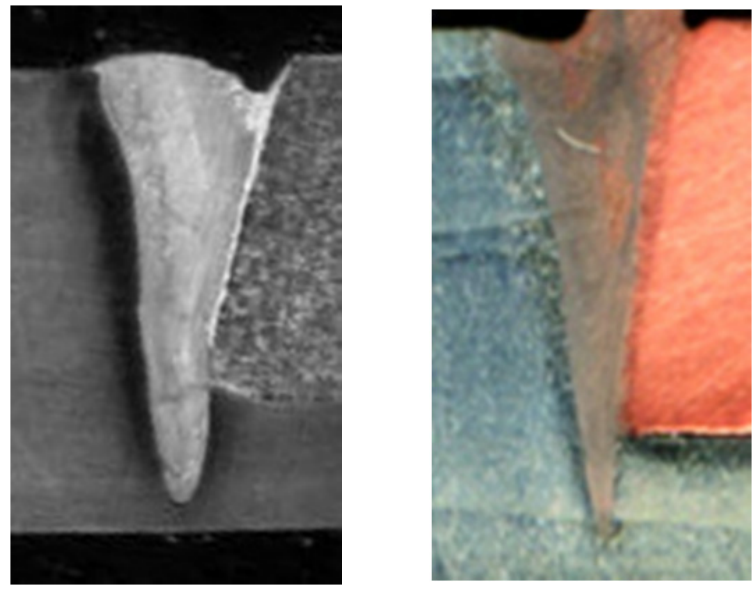

Figure 4. The weld of martensite steel 09X16H4B with bronze $\mathrm{BrX}-08$, thickness $7.5 \mathrm{~mm}$

Moreover, as the thickness of welded metal increases, a considerable asymmetry of the weld to the bronze part appears and the complete penetration of metals becomes impossible (Goncharov et al., 2012, Karcher et al., 2009, Tomashchuk et al., 2010). This is because welded materials have different thermal conductivity coefficients and different electromagnetic properties. To get the complete penetration, to prevent steel and bronze from stirring and to reduce diffusion zones, EBW is conducted with beam shifting from the junction to steel or to bronze (Goncharov et al., 2012; Karcher et al., 2009; Tomashchuk et al., 2010; Turichin et al., 2013). This processing method allows melting one metal while the other is melted insignificantly, and the weld is carried out by braze welding (Tomashchuk et al., 2010). However, this method requires a precise positioning of the electron beam because even slight deviations can cause either incomplete fusion or steel-bronze stirring and weld defects (Goncharov et al., 2012; Karcher et al., 2009; Klimova et al., 2013). The heterogeneous welds with small thickness can give satisfactory results (Turichin et al., 2013).

The formation of heterogeneous complex metal weld structure in the EBW of steel with bronze by the junction can be explained the following way. As it was mentioned above, the heterogeneousness of dissimilar metal welds depends on convective flows in welding pool. Fluid convection is caused by different fluid temperature in different zones of welding pool, as well as some other reasons. For example, in arc welding, the pressure of welding arc and electric forces provoke the turbulent flow of liquid in central part. Besides, a layer where the stirring of liquid metals is almost absent appears in weld metal near the fusion boundary (Rabkin et al., 1975).

More complex physical processes run in EBW with deep penetration. The electron beam melts the metal by the front wall of penetration channel. The periodic movement of electron beam along the front wall of the channel causes the generation of liquid phase of the metal from time to time. This leads to the complex flow of hydrodynamic processes deep in the welding pool (Rykalin et al., 1985; Nazarenko and Kaidalov, 1987; Rai et al., 2009). In paper (Bashenko et al., 1993), there is a scheme of melt flow in welding pool in EBW. In the upper part of the channel, where its vee angle is small, the metal is transferred mainly horizontally by side walls from the penetration front to the tail of the welding pool, where the liquid flow is turbulent. In middle and lower parts of the channel, where the depth of its vee angle falls considerably, the metal transfer along the axe of the beam considerably intensifies. The metal is transferred from the melt front discretely, by single portions according to the conditions of self-oscillation in the channel. The metal is transferred by the front and side walls of the channel under the influence of metal vapor recoil. On the rear wall of the channel, there are the upstreams of metal involved in joint movement by the vapor escaping from the channel (Bashenko et al., 1993).

So, as the cooling rate is high, the lifetime of welding pool is short and melts have different properties (viscosity, wettability and surface tension), there will be no intensive interpenetration of welded metals. The melt layers of welded metals will stir in welding pool with a slight mutual dressing. At the same time, the melt layers will be larger in the upper wide part of the channel due to the turbulent movement of liquid. Besides, drop inclusions of different size will be found. In the middle and lower parts of the welding pool, the layers of melt will become 
smaller, the number of drop inclusions and their size will decrease and the metal will be dressed by the other one. Figure 5 shows the weld microstructure of martensite steel 09X16Н45 and bronze БpX-08, thickness $7.5 \mathrm{~mm}$. Many researchers observe such stirring (Figure 6).

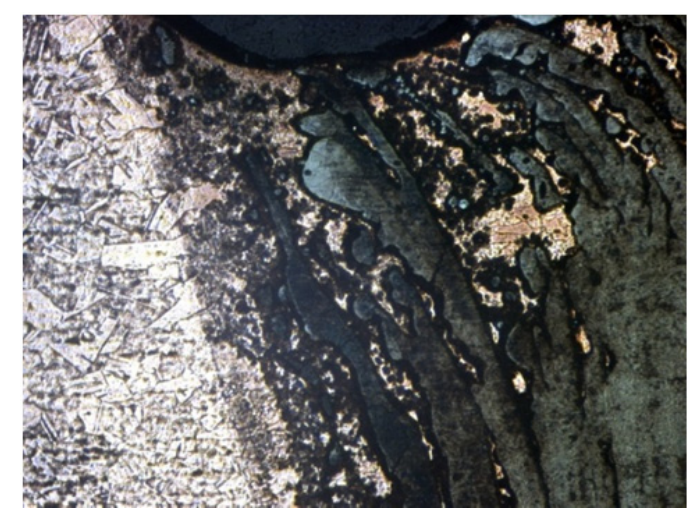

a

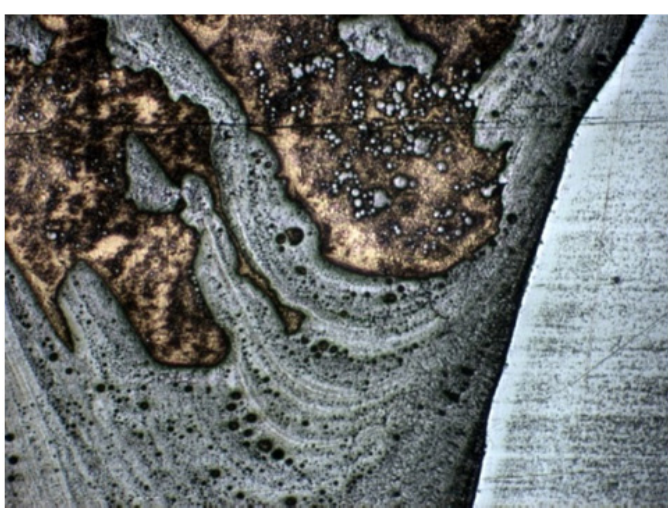

C

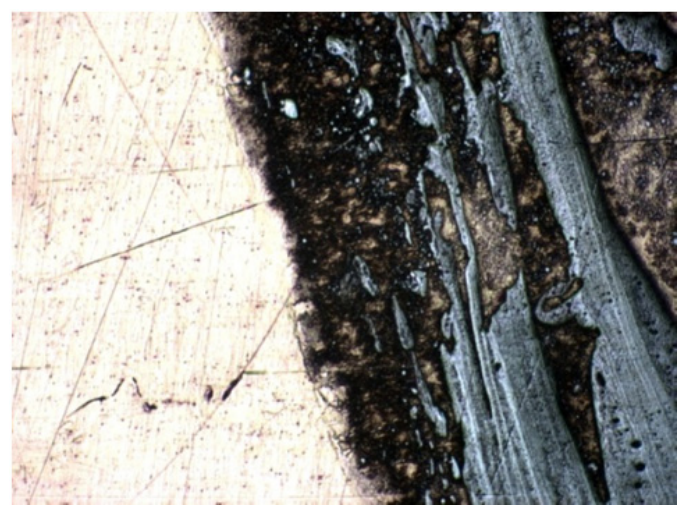

b

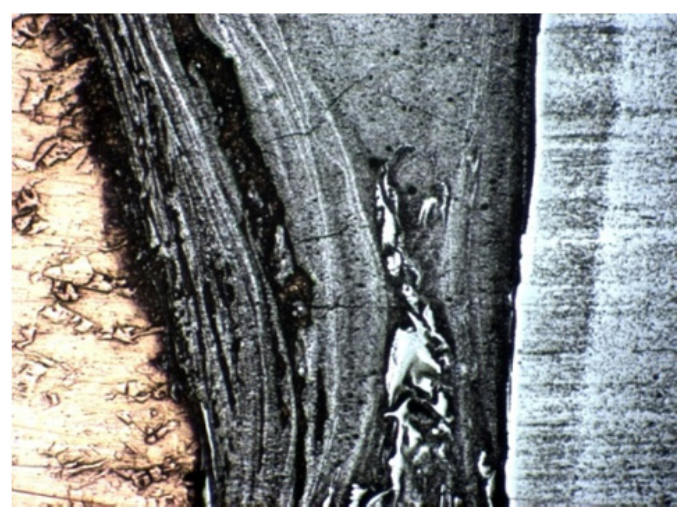

d

Figure 5. The microstructure of a weld made from martensite steel $09 \mathrm{X} 16 \mathrm{H} 4 \mathrm{~B}$ and bronze $\mathrm{BrX}-08$, zoom $\times 250$ : $\mathrm{a}$ - the upper part of the weld from the bronze side; $\mathrm{b}, \mathrm{c}-$ the middle part of the weld; $\mathrm{d}$ - the lower part of the weld

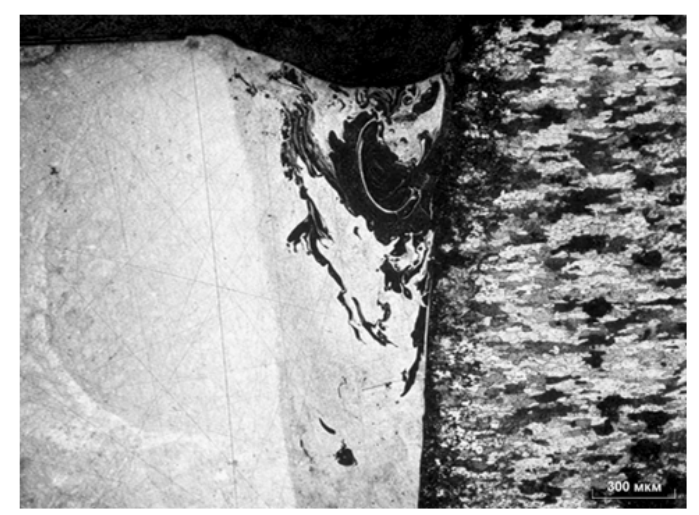

Figure 6. The upper part of the steel-bronze weld (Turichin et al., 2013)

Due to the considerable difference of crystallization temperatures, the welding pool begins to crystallize from the steel side. In the welding pool itself, the areas of liquid, where the chemical composition of the melt is close to the composition of steel, will solidify in the first place. The areas of liquid close to bronze by chemical composition will be the last to solidify filling intercrystalline and interdendritic areas and layers. During 
crystallization, the heat flow will be directed from the heating zone to bronze because the thermal conductivity of bronze is higher. Thus the liquid-state time of the welding pool on the side of bronze will increase. All this leads to the heterogeneous structure of weld metal both by depth and width.

It is impossible to influence such mechanism of crystallization by changing such parameters of EBW as electron beam current and welding speed. It only allows changing the degree of stirring and dispersivity of structures while crystallization is in all cases followed by the heterogeneous structure of weld metal with typical layers of hydrodynamic stirring based on steel or bronze with drop inclusions of steel. This mechanism of weld formation and the unevenness of thermal fields by depth and width can explain the incomplete fusion or steel-bronze stirring during the welding of high thickness with beam shifting relative to the junction.

Consequently, in deep steel-bronze EBW, the structure of weld metal will be heterogeneous by depth and width, as well as its mechanical and operating characteristics, regardless of welding conditions and metal thickness. To reduce the heterogeneousness of weld metal structure it is necessary that liquid welding pool has homogenuous content. In this case the crystallization will run with the intracrystalline segregation of copper. It means that firstly steel will crystallize in the whole volume of the welding pool while bronze will fill the interdendritic space. At that, the two systems - steel and bronze - will form a homogeneous mixture.

The conditions providing homogeneous welding pool include its intensive stirring and the increase of its liquid state. Besides, it is necessary to reduce the temperature gradient between steel and bronze for the equal heat removal rate in both metals. Such influence over the welding pool is possible by processing methods, such as the oscillation of electron beam, the concurrent heating of bronze and the splitting of electron beam into several heat sources (Bashenko et al., 2008, Nazarenko and Kaidalov, 1987, Rüthrich et al., 2011, Rüthrich et al., 2012).

\subsection{Research Objective}

The objective of this paper is to study how the different oscillation patterns of electron beam influences the structure and properties of welds in the EBW of high-alloy corrosion resistant steel with bronze.

\section{Research Methods}

The experimental studies were conducted using the high-alloy corrosion resistant steel of 12X21H5T austenitic-ferrite class and $\mathrm{BrX}-08$ chromium bronze (Table 2).

Table 2. The chemical composition of welded materials.

\begin{tabular}{cccccccccccccc}
\hline Material & \multicolumn{10}{c}{ The content of elements, \% (mass.) } \\
\cline { 2 - 7 } & $\mathrm{C}$ & $\mathrm{Cr}$ & $\mathrm{Ni}$ & $\mathrm{Ti}$ & $\mathrm{Si}$ & $\mathrm{Mn}$ & $\mathrm{S}$ & $\mathrm{P}$ & $\mathrm{Cu}$ & $\mathrm{Al}$ & $\mathrm{Fe}$ & $\mathrm{Zn}$ \\
12X21H5T & $0.09 \ldots 0.14$ & $20.0 \ldots 22.0$ & $4.8 \ldots 5.8$ & $0.25 \ldots 0.5$ & - & up to 0.8 & up to 0.025 & up to 0.035 & - & up to 0.8 & - & - \\
БрX-08 & - & $0.4 \ldots 1$ & - & - & - & - & - & - & $98.5 . .99 .6$ & - & до 0.08 & до 0.3 \\
\hline
\end{tabular}

The welding was performed by an electron-beam machine with generating unit ELA-60/6Vch produced by SELMI (Ukraine). During the experiment, we conducted welding passes by a ring-shaped junction (diameter 120 $\mathrm{mm}$ ) with halving. The thickness of the steel part was $7.5 \mathrm{~mm}$, the thickness of the bronze part was $5.5 \mathrm{~mm}$. EBW was used with various processing methods including electron beam oscillation across the junction, the $\mathrm{X}$-shaped path of the electron beam, and the splitting of the beam into several heat sources that promoted metal melting and the concurrent heating of bronze. When using the oscillatory movement of the electron beam along the junction, the character of hydrodynamic processes in welding pool change and the melt is stirred more intensively. When the electron beam is splitted into three heat sources one after another with high power concentration (Figure 7), the weld is formed similarly to deep multiple-pass welding. This provides the additional stirring of metal (Rüthrich et al., 2011, Rüthrich et al., 2012). The bronze part is heated by the splitted raster source near the junction. This compensates the unevenness of heat removal from the welding zone due to the higher thermal conductivity of bronze. Besides, several heat sources lengthened the welding pool and its liquid-state time. EBW conditions were chosen on the assumption of full penetration. They are given in Table 3 . 


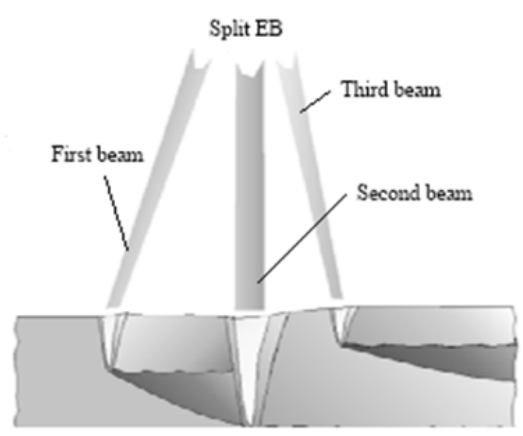

a

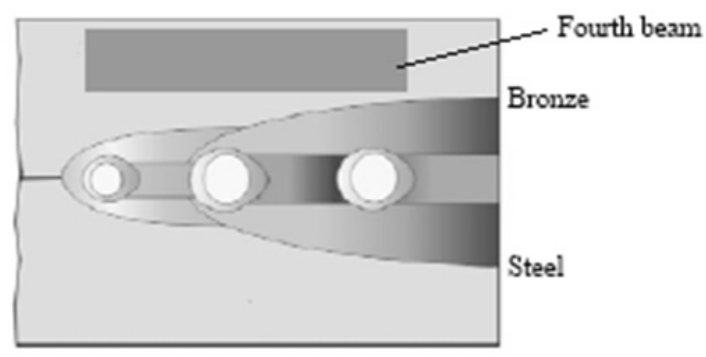

b

Figure 7. The scheme of electron beam splitting in welding: a - cross section; b - top view (Rüthrich et al., 2011, Rüthrich et al., 2012)

Table 3. Steel-bronze EBW conditions

\begin{tabular}{lccccccccc}
\hline Type of sweep & \multicolumn{3}{c}{ Beam parameters } & \multicolumn{3}{c}{ Oscillation parameters } & \multicolumn{3}{c}{ Beam power splitting, \% } \\
\cline { 2 - 10 } & $\mathrm{U}, \mathrm{kV}$ & $\mathrm{I}, \mathrm{mA}$ & $\mathrm{V}, \mathrm{mm} / \mathrm{s}$ & Amplitude, & Frequency, & 1 beam & 2 beam & 3 beam & $4 \mathrm{beam}$ \\
& & & & $\mathrm{a}, \mathrm{mm}$ & $\mathrm{f}, \mathrm{Hz}$ & & - & - \\
Transverse & 60 & $32 \ldots 34$ & 5 & 0.8 & 600 & - & - & - & - \\
X-shaped & 60 & $32 \ldots 34$ & 5 & 0.8 & 600 & - & - & - \\
Beam splitting & 60 & 85 & 6 & - & - & 21.1 & 29.6 & 18.3 & 31 \\
\hline
\end{tabular}

The metallographic study of weld cross section was performed using MIM-10 microscope with VideoTest Metal software package. The etching was performed by Vasilyev's reagent. The mechanical characteristics of the weld were evaluated by measuring microhardness using PMT-3 instrument. Chemical composition in different areas of welds was ascertained by X-ray spectrum analysis with the help of REM-100U scanning electron microscope.

\section{Results and Discussion}

The experimental research resulted in welds with macrostructure shown in Figure 8 and dimensions given in Table 4.

Table 4. The geometrical characteristics of welds

\begin{tabular}{|c|c|c|c|c|}
\hline \multirow[t]{2}{*}{ Welding method } & \multirow[t]{2}{*}{ Weld height, mm } & \multicolumn{3}{|c|}{ Weld width, mm } \\
\hline & & Upper part & Middle part & Root part \\
\hline With transverse oscillation & 7 & 2.9 & 1.1 & 0.5 \\
\hline With X-shaped oscillation & 7.5 & 3.2 & 1.8 & 0.6 \\
\hline With beam splitting & 7.3 & 4.3 & 1.8 & 0.6 \\
\hline
\end{tabular}

The metallographic analysis of weld macrostructure showed that, during the welding, metal is stirred in all studied cases but its character was different. In EBW with transverse beam oscillation, there is a metal layer with different colour in the macrostructure of weld on the side of steel and a large drop inclusion of the same colour in the centre of the upper part of the weld (Figure 8, a). In welding with X-shaped beam oscillation, such metal layer is also found on the side of steel, but it has a wavy saw-tooth boundary (Figure 8, b). In welding with beam splitting, the weld metal looks homogeneous in large section (Figure 8, c). 


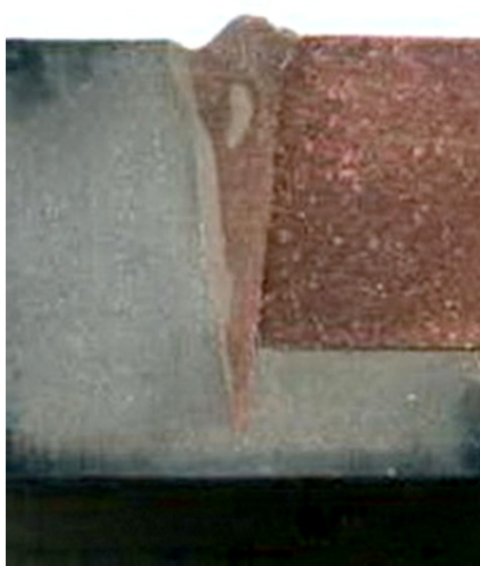

a

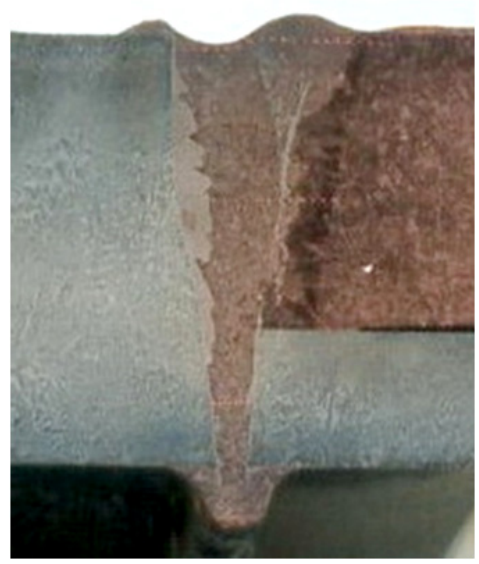

b

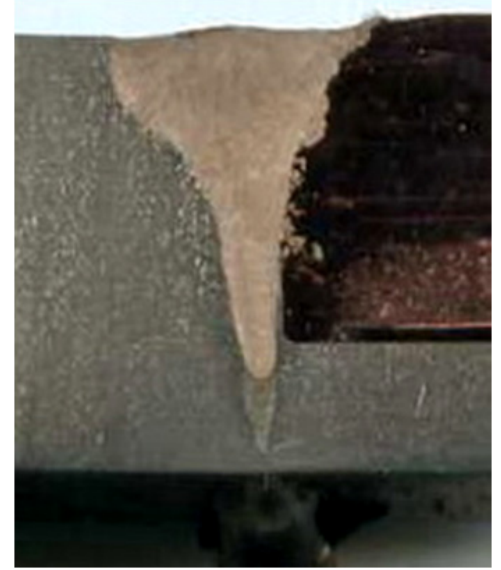

c

Figure 8 . The macrostructure of welds $($ zoom $\times 6)$ : $a-$ transverse oscillation; $b-X$-shaped oscillation; $c-b e a m$ splitting

The study of weld microstructure showed that the transverse oscillation of electron beam in welding leads to the heterogeneous structure both by the depth and width of the weld (Figure 9). By width, three typical areas can be singled out. The first area is formed on the steel side, where the weld metal is based on steel, which is a mixture of two phases of austenite and ferrite with drop intercrystalline and interdendritic inclusions of bronze (Figure 10, a). The second area is the central part of the weld, which is based on bronze, while steel forms large inclusions in it. They are also drop-shaped and mainly dendritic (Figure 4, c). Inside steel inclusions, one can see the intercrystalline and interdendritic layers of bronze. There is an abrupt junction between the first and second typical areas of the weld (Figure 10, b). The third area is formed on the side of bronze where dendritic steel formations become bigger and drop formations acquire an elongated shape (Figure 10, c). These typical areas change their dimensions by depth (Figure 9).

In the weld obtained by the $\boldsymbol{X}$-shaped oscillation of electron beam, there are the same typical structures with some distinctions (Figure 11). The boundary between the first and second typical areas becomes wavy and saw-tooth (Figure 12, a). In the second typical area, the drop-shaped and dendritic formations of steel begin to grow (Figure 12, b). In the third typical area, the elongated inclusions of steel merge into one big formation (Figure 12, c).

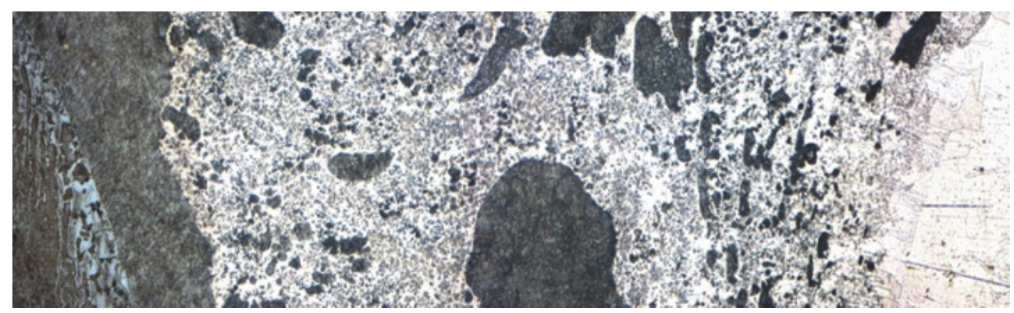

a

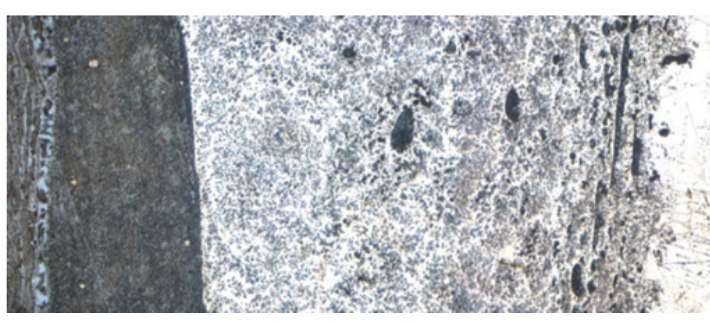

b

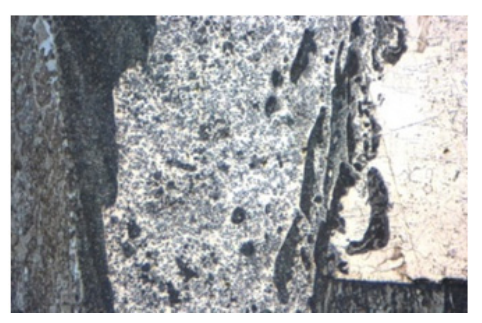

c

Figure 9. The microstructure of the weld obtained with transverse beam oscillation (zoom $\times 100)$ : a - the upper part; $\mathrm{b}$ - the middle part; $\mathrm{c}-$ the root part 


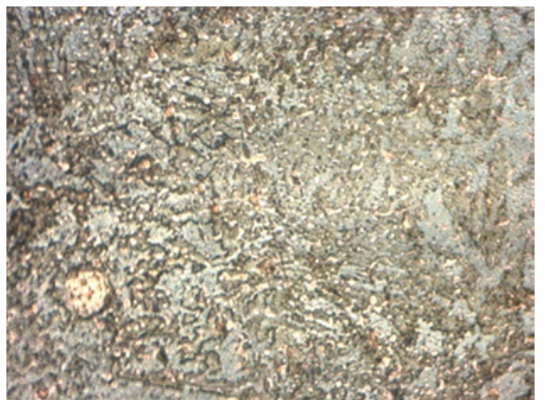

a

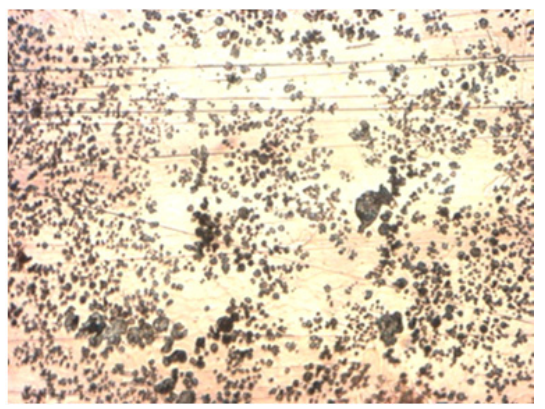

c

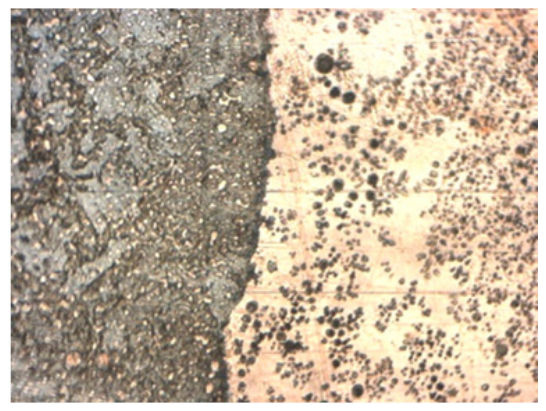

b

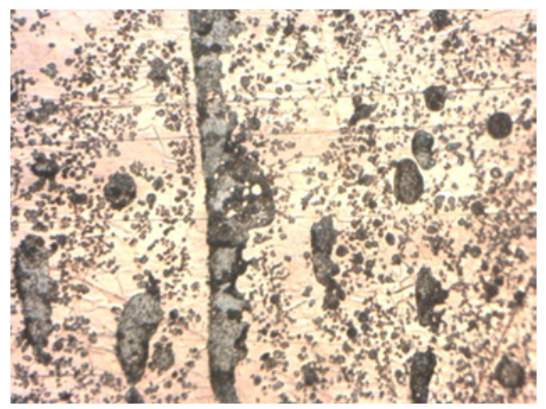

d

Figure 10. The microstructure of the weld obtained with transverse oscillation (zoom $\times 600)$ : $a-$ the first typical area; $b$ - the boundary between the first and second areas; $c, d-$ the second and third typical areas, respectively

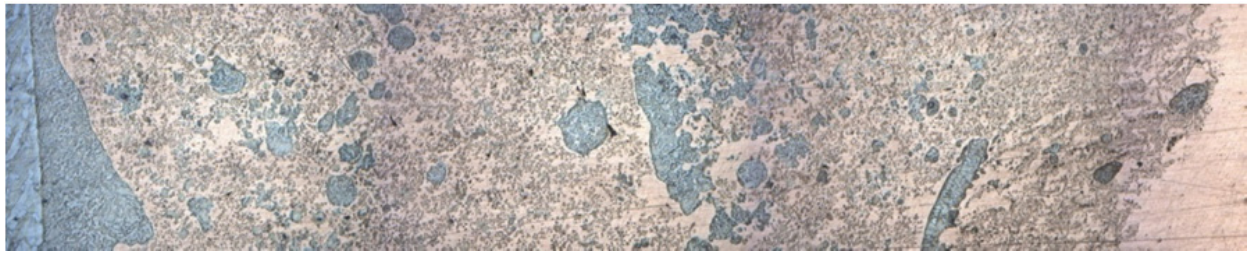

a

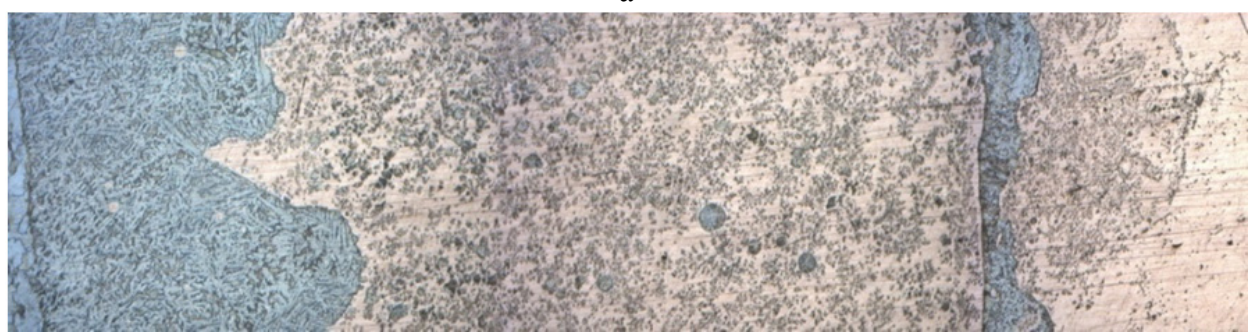

b

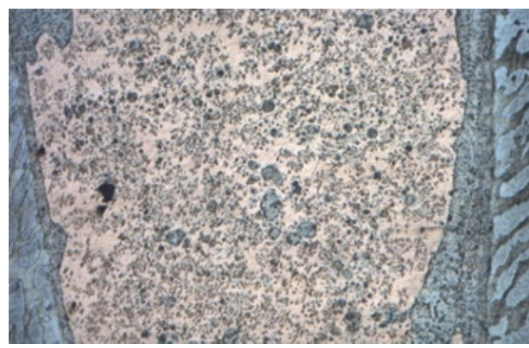

c

Figure 11. The microstructure of the weld obtained by $X$-shaped beam oscillation $($ zoom $\times 100)$ : $a-$ the upper part; $\mathrm{b}$ - the middle part; $\mathrm{c}$ - the root part 


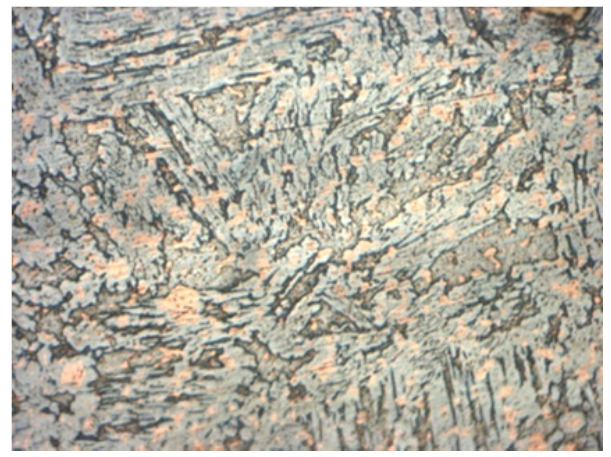

$\mathrm{a}$

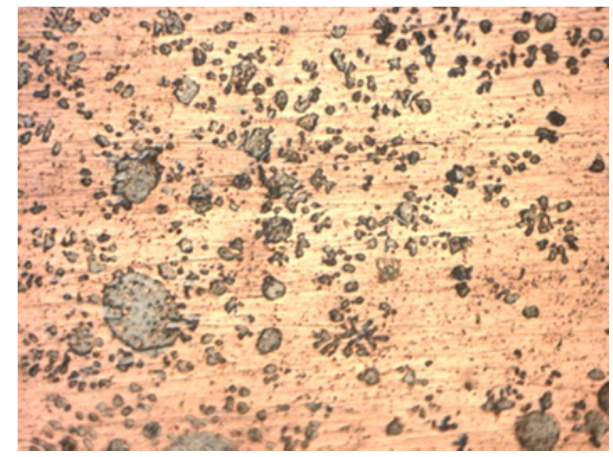

b

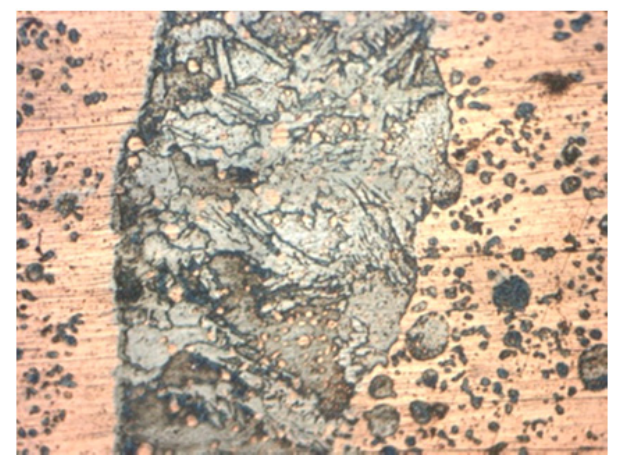

c

Figure 12. The microstructure of the weld obtained by X-shaped beam oscillation (zoom $\times 600)$ : $a, b, c-$ the first, second and third typical areas, respectively

It should be noted that the structure of welds performed with beam oscillation was free from typical defect as the intercrystalline penetration of copper into steel. The character of formed structures and the absence of intercrystalline penetration indicate the influence of beam oscillation on hydrodynamic processes. The X-shaped oscillation has the strongest influence. They cause the most intensive melt stirring in each typical area. This is confirmed by X-ray spectrum analysis (Table 5). To perform a high-quality evaluation of structures formed in each typical zone, one can use triple diagrams of state $\mathrm{Fe}-\mathrm{Cr}-\mathrm{Cu}$ (Dreval', 2011, Wang et al., 2002) because austenitic-ferrite steels contain much more chromium (more than 20\%) in comparison with nickel and other elements. Figure 13 shows the isothermal cross-section of diagram $\mathrm{Fe}-\mathrm{Cr}-\mathrm{Cu}$ for different temperature. By comparing the microstructure of typical areas and diagrammatic data, one can suppose that, in the first typical area, two solid solutions [alpha] (Fe, $\mathrm{Cr}$ ) and [gamma] (Fe, $\mathrm{Cr}$ ) mix with copper which fills the intercrystalline and interdendritic space; the second typical area is based on copper with the drop-shaped and dendritic inclusions of solid solution [gamma] ( $\mathrm{Fe}, \mathrm{Cr}$ ). The third area, near bronze, is a combination of two previous areas: the base has large inclusions with structure similar to inclusions in the first area.

Table 5. The results of the X-ray spectrum analysis.

\begin{tabular}{llcccccc}
\hline Welding method and areas of chemical composition analysis & \multicolumn{5}{c}{ The content of chemical elements, \% } \\
\cline { 3 - 7 } & & $\mathrm{Fe}$ & $\mathrm{Cu}$ & $\mathrm{Cr}$ & $\mathrm{Ni}$ & $\mathrm{Mn}$ & $\mathrm{Si}$ \\
With transverse oscillation & 1 area (Fig. 10,a) & base & 5 & 19,9 & 4.9 & 0.2 & 0.2 \\
& 2 area (Fig. 10,b) & 15.3 & base & 2.9 & 1.7 & 0.2 & 0.2 \\
With X-shaped oscillation & 1 area (Fig. 12,a) & base & 25.3 & 15.9 & 3.8 & 0.3 & 0.2 \\
& 2 area (Fig. 12,b) & 26 & base & 5 & 2 & 0.3 & 0.2 \\
& 3 area (Fig. 12,c) & base & 23.5 & 20.7 & 4.6 & 0.1 & 0.1 \\
\hline
\end{tabular}




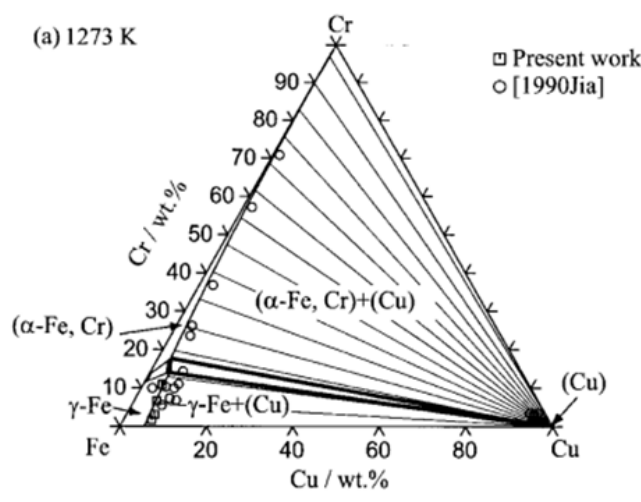

a

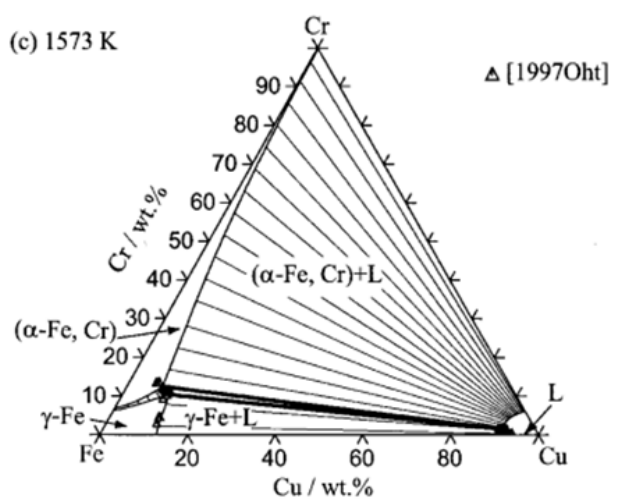

6

Figure 13. The isothermal cross-sections of diagram $\mathrm{Fe}-\mathrm{Cr}-\mathrm{Cu}$ for $1273 \mathrm{~K}$ (a) and $1573 \mathrm{~K}$ (b) (Wang et al., 2002)

So, the transverse and X-shaped oscillation of electron beam does not ensure the sufficiently intensive stirring of welding pool metal. Moreover, typical areas in the structure of weld cross-sections indicate that the reduction of temperature gradient between steel and bronze is not ensured. As a result, the weld crystallization begins on the side of steel and ends near bronze.

When EBW is performed with electron beam splitting into three concentrated heat sources and one raster source, which provides the concurrent heating from the bronze side, a homogeneous structure is formed in the weld both by depth and width (Figure 14). The X-ray spectrum analysis showed the following content of chemical elements in the weld: $\mathrm{Fe}-$ base; $\mathrm{Cu}-24.6 \% ; \mathrm{Cr}-14.5 \% ; \mathrm{Ni}-3.5 \% ; \mathrm{Mn}-0.2 \%$; $\mathrm{Si}-0.2 \%$. The microstructure of weld metal is a fine-dispersed mechanical mixture of two systems according to triple diagram $\mathrm{Fe}-\mathrm{Cr}-\mathrm{Cu}$ (Figure 13). The first system includes steel dendrites, which are the mixture of solid solutions based on [alpha](Fe, $\mathrm{Cr}$ ) and [gamma](Fe, $\mathrm{Cr})$. The second system includes drop formations and interdendritic layers based on $\mathrm{Cu}$. If we suppose that there is a full penetration of two liquid solutions, then, according to diagram $\mathrm{Fe}-\mathrm{Cu}$, this must be eutectic consisting of copper and a solid copper solution ([gamma](Cu)). The obtained structure changes its dispersity by the depth of the weld (Figure 15).

This processing method allowed creating conditions for evening the speed of heat removal into both welded metals and intensive melt stirring in the welding pool along the whole depth of the weld. For full penetration, one should correct EBW conditions.

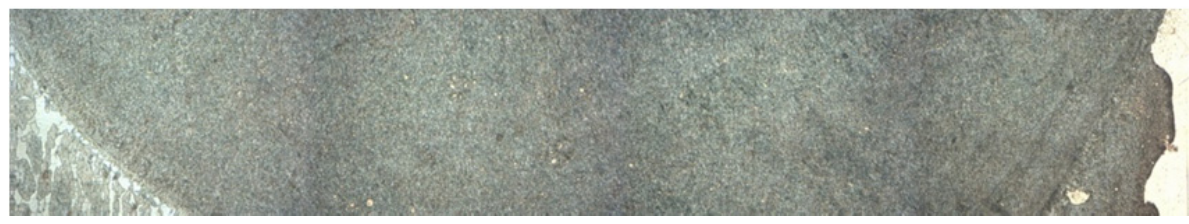

a

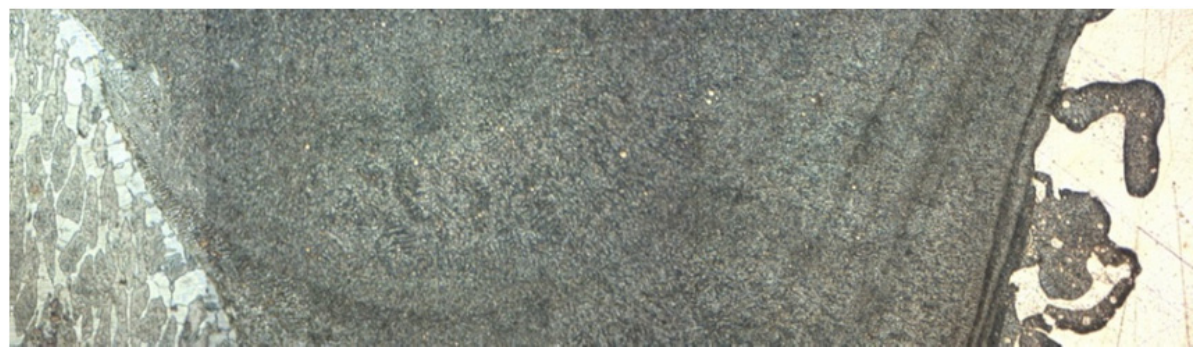

$\mathrm{b}$

Figure 14. The microstructure of the weld obtained by X-shaped beam oscillation $(\mathrm{zoom} \times 100)$ : a - the upper part; $b$ - the middle part 


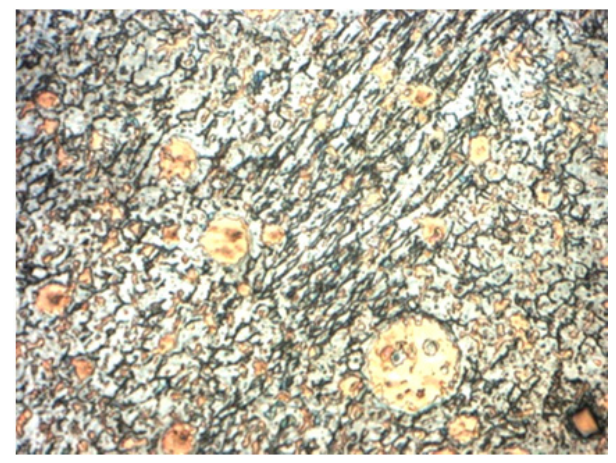

a

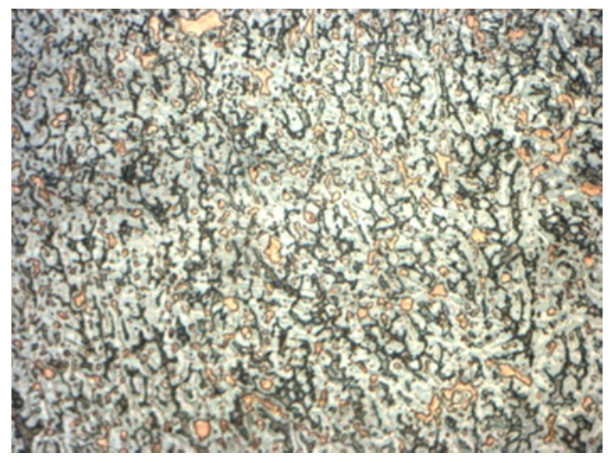

$\mathrm{c}$

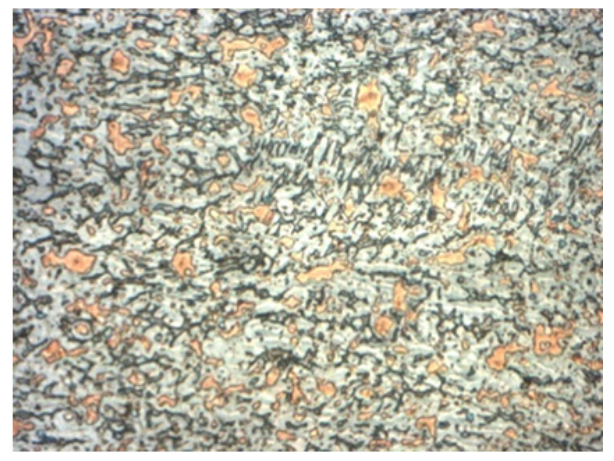

b

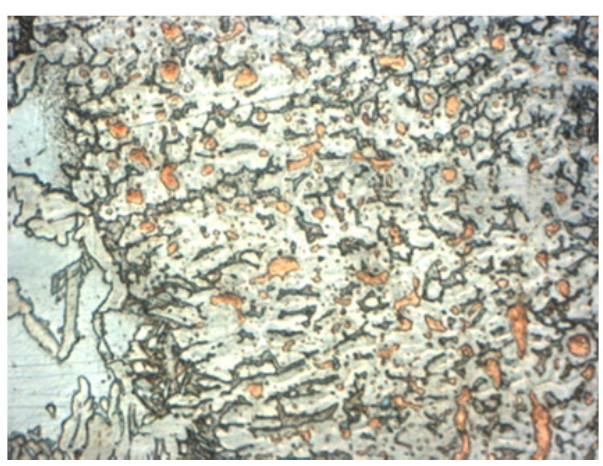

d

Figure 15. The microstructure of the weld obtained by beam splitting (zoom $\times 600)$ : $a, b, c-$ in the upper, middle and root part of the weld, respectively; $\mathrm{d}$ - the zone of steel-bronze fusion

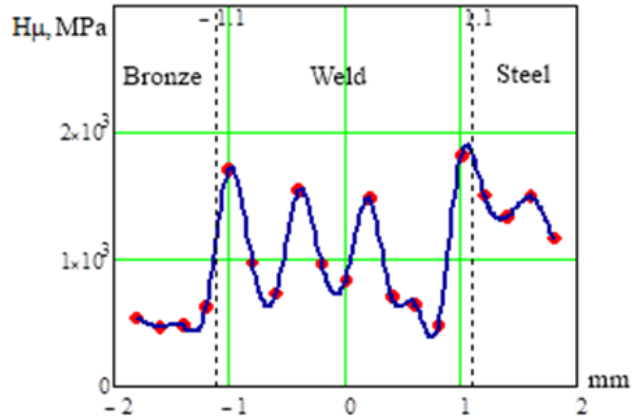

a

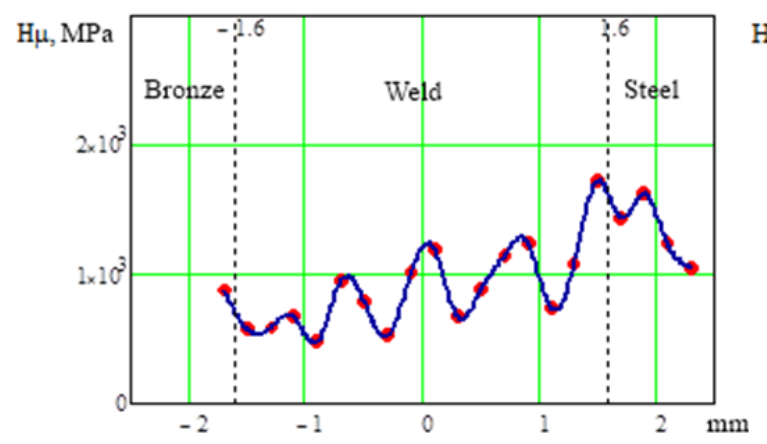

c

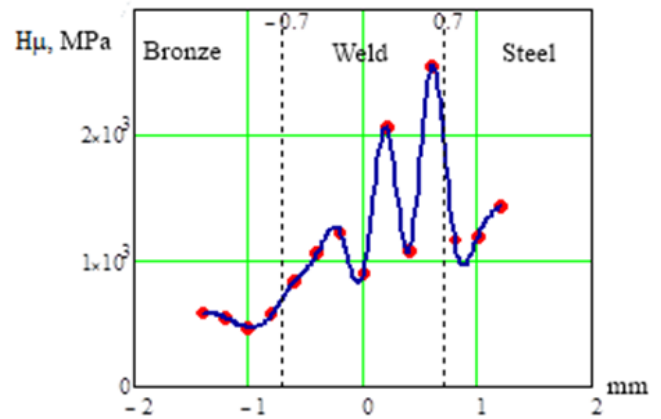

b

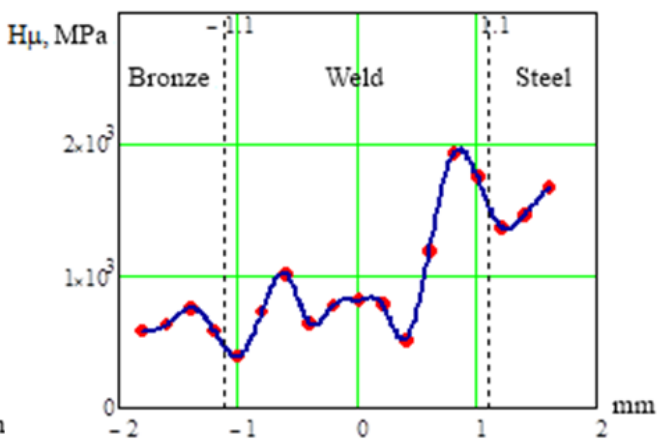

d 


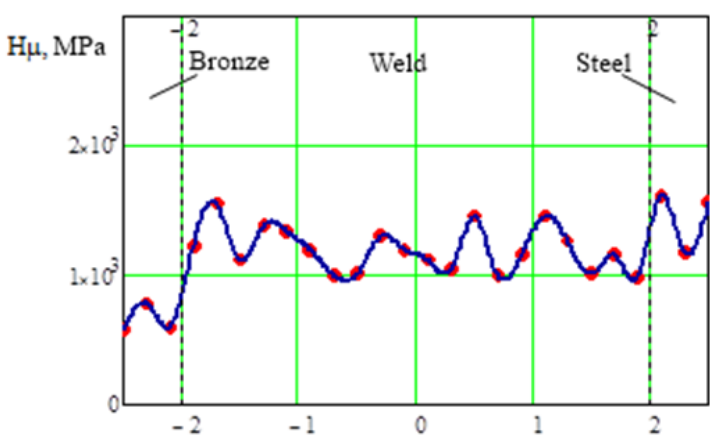

e

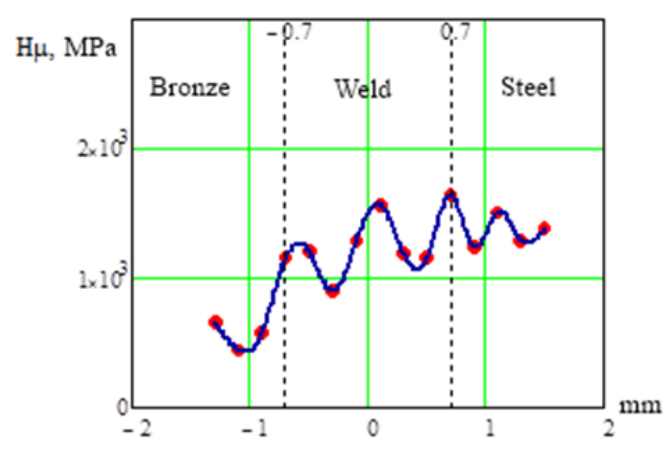

f

Figure 16. Microhardness by the width of welds: $a, b$ - with transverse beam oscillation; $c, d-$ with X-shaped beam oscillation; e, $\mathrm{f}$ - with beam oscillation; in the upper part $(\mathrm{a}, \mathrm{c}, \mathrm{e})$ and in middle part $(\mathrm{b}, \mathrm{d}, \mathrm{f})$

The mechanical properties of welds and their homogeneousness were evaluated by microhardness. Microhardness was measured by the width of welds in the upper and middle parts. The results of measurements are shown in Figure 16. The heterogeneous structure of welds obtained by EBW with transverse and X-shaped oscillation cause the heterogeneousness of weld metal properties. By the width of welds, microhardness changes unevenly. Besides, there is a considerable drop between its highest and lowest values both by the width and depth of welds (Figure 16, a, b, c, d). If the beam has an X-shaped oscillation path, the dispersion of microhardness values slightly reduces as compared with transverse oscillation. The method of electron beam splitting into several heat sources promotes a sufficiently even microhardness of metal both by the width and depth of the weld (Figure 16, e, f).

\section{Conclusions}

The steel-bronze EBW with the transverse or X-shaped oscillation of electron beam does not ensure the homogeneous structure and properties of weld metal.

The steel-bronze welds of high quality with high mechanical and operating characteristics at the expense of homogeneous weld metal is achieved by electron beam splitting into three concentrated heat sources and one raster source which provides the concurrent heating of weld metal on the side of bronze.

\section{References}

Bashenko, V. V., Detsik, N. N., \& Detsik, V. N. (1993). On the motion of the melt in the weld pool in EBW: Proceedings of the scientific and technical conference on EBW. Moscow.

Bashenko, V. V., Vikhman, V. B., Kozlov, A. N., \& Gaydukova, I. S. (2008). State and prospects development of electron beam welding: Proceedings of the International Scientific and Technical Conference Technologies and equipment of electron beam welding. St. Petersburg.

Dreval, L. A. (2011). Thermodynamic properties alloys of liquid copper and iron with chromium, cobalt and nickel. Abstract of the thesis.

Goncharov, L. A., Terentyev, E. V., Marchenkov, A. U., \& Portnov, M. A. (2012). Electron beam welding of bronzes to $316 \mathrm{~L}(\mathrm{~N})$ steel. Electrotechnica \& Electronica, 5(6), 123-127.

Karcher, C., Ziolkowsk, M., \& Brauer, H. (2009) Seeback Effect during Electron Beam Welding. Elektrotechnica \& Electronica, 5(6), 76-81.

Klimova, O. G., Turichin, G. A., Lopota, V. A., Shamshurin, A. I., \& Sizov, I. A. (2013) Stricture features of metal welding by electron beam welding of dissimilar materials. Nauchno-Tekhnicheskie Vedomosti Spbgpu, 2, 125-132.

Liakishev, N. P. (1997). Diagrams of condition binary metal system. Volume 2. Mashinostroyeniye.

Magnabosco, I., Ferro, P., Bonollo, F., \& Arnberg, L. (2006). An investigation of fusion zone microstructures in electronbeam welding of copper-stainless steel. Materials Science and Engineering, A 424, 163-173.

Nazarenko, O. K., \& Kaidalov, A. A. (1987). Electron beam welding. Kiev: Naukova Dumka.

Rabkin, D. M., Ryabov, V. R., \& Gurevich, S. M. (1975). Welding of dissimilar materials. Kiev: Tekhnika. 
Rai, R., Palmer, T. A., Elmer, J. W., \& Debroy, T. (2009). Heat transfer and fluid flow during Electron beam welding of 304L stainless steel alloy. Welding Journal, 88, 54-61.

Rüthrich, K., Zenker, R., \& Freiberg, D. (2012). Characteristics and Prospects of Process Integrated Thermal Field Heat Treatment for Electron Beam Welding of Cast Iron. DVS BERICHTE, Electron beam welding Conference; 2nd, Electron beam welding.

Rüthrich, K., Zenker, R., \& Mangler, M. (2011). Electron beam multipool welding with thermal fields of metal welds based on cast iron.

Ryabov, V. R., Rabkin, D. M., \& Kurochko, R. S. (1984). Welding of dissimilar metals and alloys. Moscow: Mashinostroyeniye.

Rykalin, N. N., Uglov, A. A., Zuev, I. V., \& Kokora, A. N. (1985). Laser and electron-beam processing of materials, Handbook. Moscow: Mashinostroyeniye.

Tomashchuk, I., Sallamand, P., Jouvard, J. M., \& Grevey, D. (2010). The simulation of morphology of dissimilar copper-steel electron beam welds using level set method. Computational Materials Science, 48, 827-836.

Turichin, G. A., Klimova, O. G., Babkin, K. D., \& Pevzner, Ya. B. (2013). Effect of thermal and diffusion processes on formation of the structure of weld metal due to laser welding of dissimilar materials. Metal Science and Heat Treatment, 10, 58-64.

Volchenko, V. N. (1991). Welding and welding materials: In three volumes. Volume I. Weldability of materials. Handbook. Moscow: Metallurgiya.

Wang, C. P., Liu, X. J., Ohnuma, I., Kainuma, R., \& Ishida, K. (2002). Phase Equilibria in Fe-Cu-X (X: Co, Cr, $\mathrm{Si}, \mathrm{V})$ Ternary Systems. Journal of Phase Equilibria, 23(3), 236-245.

Wielage, B., Steinhäuser, S., Alisch, G., Podlesak, H., \& Dietrich, D. (2007). Microstructure analysis of a bronze-steel electron beam weld. Microchim Acta, 156, 95-98.

\section{Copyrights}

Copyright for this article is retained by the author(s), with first publication rights granted to the journal.

This is an open-access article distributed under the terms and conditions of the Creative Commons Attribution license (http://creativecommons.org/licenses/by/3.0/). 